\title{
Drug point
}

\section{Danger of interaction between ciprofloxacin and theophylline}

Drs J L BEM and R D MANN (Committee on Safety of Medicines, London SW8 5NQ) write: Ciprofloxacin (Ciproxin, Bayer), a new fluoroquinolone antibiotic, was introduced in 1987 for the treatment of systemic infections. Quinolone antibiotics, including ciprofloxacin, inhibit theophylline metabolism and both prolong and raise plasma theophylline concentrations. ${ }^{1}$ A warning about this is included in the ciprofloxacin datasheet. A potentially dangerous situation occurs when a patient already being treated with theophylline is prescribed ciprofloxacin for a respiratory tract infection. The early signs of theophylline overdose, nausea and vomiting, may easily be overlooked or attributed to the side effects of ciprofloxacin.
The Committee on Safety of Medicines has received eight reports of clinically important interaction between ciprofloxacin and theophylline (table). In most cases the dose of both drugs was well within the recommended range. The signs and symptoms of drug interaction appeared rapidly, usually two to three days after the start of ciprofloxacin. One elderly woman treated with moderate doses of theophylline died with a toxic plasma concentration after a coadministered short course of ciprofloxacin.

Thomson et al observed twofold to threefold increases in the concentration and $64 \%$ reduction in clearance of theophylline in elderly patients who had received ciprofloxacin $500 \mathrm{mg}$ twice daily for a few days. ${ }^{2}$ An interaction between ciprofloxacin and theophylline is not inevitable ${ }^{3}$ and we have four reports of patients given both drugs who developed adverse reactions due to other causes. Thus it is difficult to predict which patients are at risk of this interaction, and we suggest that ciprofloxacin should not normally be used in patients treated with theophylline. Patients should also be warned against self medication as some cough-cold medicines contain theophylline. In cases in which ciprofloxacin and theophylline need to be given together plasma theophylline concentrations should be monitored.

1 Wijnands WJA, Vree TB, Van Herwaarden CLA. The influence of quinolone derivatives on theophylline clearance. $\mathrm{Br} \mathcal{F} \mathrm{Clin}$ Pharmacol 1986;22:677-83.

2 Thomson AH, Thompson GD, Hepburn M, Whiting B. A clinically significant interaction between ciprofloxacin and theophylline. Eur f Pharmacol 1987;33:435-6.

3 Maeson FPV, Teengs JP, Baur C, Davis BI. Quinolones and raised plasma concentrations of theophylline. Lancet 1984; ii: 530 .

Yellow card reports of patients in whom interaction between ciprofloxacin and theophylline was suspected clinically or because of laboratory measurements

\begin{tabular}{|c|c|c|c|c|c|c|}
\hline $\begin{array}{l}\text { Case } \\
\text { No }\end{array}$ & Sex and age & $\begin{array}{l}\text { Ciprofloxacin } \\
\text { daily dose } \\
\text { (mg) }\end{array}$ & $\begin{array}{l}\text { Theophylline } \\
\text { daily dose } \\
\text { (mg) }\end{array}$ & Interval $\ddagger$ & Reported adverse drug reactions & Other medication \\
\hline $1^{\star}$ & $\mathrm{F}$ & 500 & 440 & 4 & $\begin{array}{l}\text { Drug interaction, articular, fibrillation, convulsions, } \\
\text { cardiovascular accident }\end{array}$ & Bumetanide, digoxin, tamoxifen \\
\hline 2 & M67 & 500 & 350 & 3 & Drug interaction, dyspnoea, abdominal pain & Diltiazem, bendrofluazide, terbutaline, budesonide \\
\hline $3+$ & M40 & ? & 440 & ? & Drug interaction, hypoaesthesia & \\
\hline 4 & M59 & 1000 & 600 & ? & Drug interaction & $\begin{array}{l}\text { Ranitidine, bumetanide, temazepam, digoxin, } \\
\text { budesonide }\end{array}$ \\
\hline 5 & F49 & 1000 & 400 & ? & Drug interaction, tachycardia, hypertension & \\
\hline 6 & F49 & 1000 & 800 & ? & Drug interaction, nausea, palpitation & $\begin{array}{l}\text { Prednisolone, amilonide and frusemide, beclomethasone, } \\
\text { salbutamol, ipratropium }\end{array}$ \\
\hline 7 & M66 & 500 & $?$ & 1 & Drug interaction, dyspnoea, asthenia, dizziness & Prednisolone, fenoterol, hydrobromide and ipratropium \\
\hline 8 & F16 & 1500 & 400 & 2 & Drug interaction, nausea, malaise & Beclomethasone, salbutamol \\
\hline
\end{tabular}

^Patient died with a theophylline concentration of $188 \mu \mathrm{mol} / \mathrm{l}$.

tPatient recovered after dose of theophylline was reduced.

$\ddagger$ Number of days between starting ciprofloxacin and onset of reaction.

\section{Points}

\section{Inappropriate dental care in casualty departments}

Miss A Seymour (Ingham Infirmary, South Shields, Tyne and Wear NE33 3PP) writes: I note the letter of Messrs I C Mackie and P Hobson (5 March, p 719) and wonder how many accident units are able to obtain the luxury of a visit from a dental surgeon-or within two hours. Our nearest hospital dental unit is about $16 \mathrm{~km}$ away in Sunderland. At night it is not uncommon for it to take three quarters of an hour to contact the dental person on call via the switchboard. When contacted our dental colleagues are extremely helpful, and the delay in contacting them is due normally to their being in the operating theatre or being in transit between the many different places they cover. If they then ask us to transfer the patient to them it often takes an hour to obtain transport. If any progress is to be made in this matter the casualty officer himself will have to take steps to replace the tooth and possibly we will have to establish an arrangement whereby such patients could be sent direct to the dental unit while attempts are made to contact the dental officer on call.

\section{Laparoscopic incisions at the lower umbilical verge}

Mr HERBERT ReISS (London WIN IPE) writes: I have read with pleasure the article by Drs Michael East and Peter Steele (12 March, p 753) on incisions for laparoscopy. I first saw the longitudinal subumbilical incision used by $\mathrm{Dr}$ Hans Frangenheim when a party of the British Fertility Society visited his clinic in Konstanz in 1976 and have used it ever since. Apart from giving a better cosmetic result, the incision can usually be closed without stitch or clip by a long strip of sticking plaster tightly applied transversely to keep the skin edges together. This saves time, causes less postoperative pain, and usually leaves an invisible scar. A stitch is required only rarely if there is persistent oozing of blood from the skin edges. I recommend this incision without the need to suture to all gynaecological laparoscopists.

Mr G T WATTS (Birmingham B13 8LD) writes: Mr Michael C East and Dr Peter R M Steele draw attention to the advantage of studying the direction of Langer's lines at the umbilicus (12 March, p 753) Simple adherence to this rule alone is not enough as it is not the line of the tissue orientation that determines the healing of a scar but the dynamic tension in the tissues at the time. Langer determined his "lines" in cadavers. We showed some time ago that the direction of the healing could be altered greatly by superimposed tension. ${ }^{1}$ Others have shown similar effects caused by different wound shapes. ${ }^{2}$ It is important to note these influences if one is not to cause apparent contradictions of Langer's principles. A simple test is to pinch up the skin in two directions, when the tension lines can be easily shown. 1 Watts GT. Wound shape and tissue tension in healing. Br $\mathcal{F}$ Surg
1960;47:555-61.

2 Billingham RE, Russel PS. Studies in wound healing with special reference to the phenomenon of contracture. Ann Surg 1956; 144:961-81.

\section{Elastic stockings}

Dr D C Holloway (Scholl (UK), London EC1P 1DH) writes: An explanation of the changes in the compression hosiery section of the Drug Tariff would have been useful in Dr Alan J Whitley's article (6 February, p 413). Compression hosiery has been grouped into three classes. Class I (previously known as lightweight elastic yarn), with $14-17 \mathrm{~mm} \mathrm{Hg}$ pressure at the ankle, is intended for early varices and varicosis during pregnancy; class II (previously standard elastic yarn) offers ankle pressures of $18-24 \mathrm{~mm} \mathrm{Hg}$ and is for medium varices and mild oedema; class III (previously one way stretch) provides $25-35 \mathrm{~mm} \mathrm{Hg}$ compression at the ankle and is for severe varices, gross oedema, post-thrombotic venous insufficiency, and the treatment of ulcers. All compression hosiery for prescription must be thigh length, below knee, anklets, or knee caps. This new tariff has simplified prescribing for general practitioners and each prescription should include: the quantity (either single or pair), article definition (thigh stocking, below knee stocking) including accessories (suspenders or suspender belt), and compression class. These new regulations allow manufacturers to produce far more acceptable but just as effective products for patients.

\section{Availability of proper officers}

Mr D F M ThOMAS (Leeds LS8 2LA) writes: Drs Mukesh Kapila and Celia Duff (5 March, p 681) draw attention to the lack of availability of community physicians to meet the emergency needs of the service. This is hardly surprising in a system which remunerates consultants equally regardless of their workload and out of hours commitments to the health service. In contrast to junior staff and administrators, consultants receive no payment for the additional work they undertake at nights and weekends. It is interesting, however, that health districts are authorised to pay their community physicians a salary which is several thousand pounds greater than that of full time NHS consultant clinicians. These include, for example, neonatologists and academic transplant surgeons, who have onerous out of hours commitments and who undertake little if any private practice. The implementation of Achieving a Balance will inevitably increase the amount of out of hours work being done by consultants in acute specialties. Surely the time has come to reconsider the way in which consultants' out of hours responsibilities are defined and remunerated. 